\title{
Pediatric HIV/AIDS in sub-Saharan Africa: emerging issues and way forward
}

\author{
${ }^{*}$ Ubesie AC
}

1. Department of Paediatrics, Faculty of Medical Sciences, University of Nigeria/University of Nigeria Teaching Hospital, Enugu, Nigeria

2. Visiting Research Scholar, Division of Gastro-enterology, Hepatology and Nutrition, Cincinnati Children Hospital, Cincinnati, Ohio, USA.

\begin{abstract}
Background: Sub-Saharan Africa has the largest burden of pediatric HIV in the world. Global target has been set for eradication of pediatric HIV by 2015 but there are still so many complex issues facing HIV infected and affected children in the sub-continent.

Objective: To review the current and emerging challenges facing pediatric HIV care in sub-Saharan Africa; and proffer solutions that could help in tackling these challenges.

Method: A Medline literature search of recent publications was performed to identify articles on "pediatric HIV", "HIV and children", "HIV and infants", "HIV and adolescents" in sub-Saharan Africa.

Result: There are a number of challenges and emerging complex issues facing children infected and affected by HIV in subSaharan Africa. These include late presentation, limited access to pediatric HIV services, delayed diagnosis, infant feeding choices, malnutrition, limited and complex drug regimen, disclosure, treatment failure and reproductive health concerns. A holistic cost effective preventive, diagnostic and treatment strategies are required in order to eliminate pediatric HIV in SSA. Conclusion: HIV infected children and their families in sub-Saharan Africa face myriad of complex medical and psychosocial issues. A holistic health promotional approach is being advocated as the required step for eradication of pediatric HIV in Africa.
\end{abstract}

Keywords: Pediatric HIV, sub-Saharan Africa, Challenges. African Health Sciences 2012; 12(3): 297 - 304 http://dx.doi.org/10.4314/ahs.v12i3.8

\section{Introduction}

Acquired Immune-Deficiency Syndrome (AIDS) was described over 3 decades ago ${ }^{1}$. Although initially identified as an isolated disease among a certain vulnerable population, it later became a worldwide pandemic. According to the 2011 progress report on Global HIV/AIDS Response, an estimated 34 million people were living with HIV by the end of 2010; 2.7 million new infections and 1.8 million deaths occurred in 2010 alone $^{2}$. Sub Saharan Africa (SSA) is occupied by $12 \%$ of the global population, but disproportionately has more than $90 \%$ of children younger than 15 years and $68 \%$ of adults that are living with $\mathrm{HIV}^{2}$. Seventy percent of the

\begin{tabular}{|l|}
\hline *Correspondence author: \\
Ubesie C Agozie \\
Department of Paediatrics \\
Faculty of Medical Sciences, University of Nigeria/ \\
University of Nigeria Teaching Hospital \\
Enugu, Nigeria \\
Email: agozie.ubesie@,unn.edu.ng
\end{tabular}

African Health Sciences Vol 12 No 3 September 2012 new infection that occurred in 2010 was also recorded in $\mathrm{SSA}^{2}$. South Africa has the highest number of people living with HIV in the world (5.6 million) while Swaziland has the highest prevalence rate of $25.9 \%{ }^{3}$. There are approximately 16.6 million AIDS orphans (children who have lost one or both parents to HIV), most of whom live in SSA $(89 \%)^{3}$. This has a significant impact on the lives of relatives and grandparents who are now responsible for the care of these children ${ }^{4}$. There is also an increase in the number of child-headed homes. Non-orphaned children whose parent(s) are HIV infected are also impacted in a number of ways. A multi-country study involving eight African countries by USAID noted that HIV orphaned and vulnerable children (OVC) are disadvantaged in schooling and malaria prevention compared to the non-OVCs ${ }^{5}$. A number of factors have been noted to fuel the epidemics in the sub-region and include poverty, illiteracy, unemployment, inequality and inequity ${ }^{6}$. Women 
account for $56-63 \%$ of the HIV infection in subSaharan Africa. This has far reaching implications because most children acquire HIV from their HIVinfected mothers during pregnancy, birth or breastfeeding 7 . An estimated $90 \%$ of pediatric HIV occurs through mother-to-child transmission (MTCT). The failure to implement prevention programs against MTCT on an appropriate scale has resulted in hundreds of thousands of preventable HIV infections among newborns ${ }^{8}$. Each day, more than 1000 children are newly infected with HIV, and an alarming 700 die from AIDS-related complications ${ }^{8}$. With international momentum for the elimination of pediatric HIV by 2015, global targets have been set to reduce new pediatric infections by $90 \%$ and population-level mother-tochild infection rates to under $5 \%$ at 18 months in breastfeeding populations ${ }^{9,10}$. This is a tall but achievable goal. However, the HIV clinicians, researchers and policy makers need to review what is being done, evaluate current and emerging challenges; and articulate next steps of achieving this target. This is the focus of this review.

\section{Methods}

Medline through PubMed (http:// www.ncbi.nlm.nih.gov/pubmed/) was searched for articles on HIV and pediatric HIV in sub-Saharan Africa. Search was limited to English-language publications, and used the following search strategy: ((Pediatric HIV) OR (HIV and children) OR (HIV and infants) OR (HIV and adolescents) OR (PMTCT) OR (sub-Saharan Africa) OR (OVC)) AND (epidemiology) OR (risk) OR (determinant) OR (incidence) OR (prevalence). The references of retrieved were inspected; and additional relevant articles were selected and reviewed.

\section{Challenges of pediatric HIV in sub-Saharan Africa and other emerging issues}

The HIV epidemic may be stabilizing but millions are still living with the virus in SSA. South Africa has the largest HIV disease burden in the world with a median sero-prevalence of $30 \%$ and over $40 \%$ in KwaZulu-Natal ${ }^{7}$. The Pediatric AIDS Clinical Trial Group (PACTG) 076 clinical trial was the first study to demonstrate that zidovudine (AZT) starting at 14 weeks gestation, intravenous in labor and for 6 weeks to the infant post-natally reduced vertical transmission by $67 \%{ }^{11}$.

Research has shown that with efficacious interventions, the risk of MTCT can be reduced to
$2 \% 7$. However, it was noted in 2004 that despite multiple HIV programs in Africa, the number of HIV infected pregnant women who utilize them is less than $5 \%{ }^{12}$. While, there have been success stories coming out of Africa with respect to the PMTCT programs, the vast majority of the affected do not have access to these programs ${ }^{7}$. Studies have also demonstrated the benefits of early care and antiretroviral therapy in reducing morbidity and mortality in HIV infected children ${ }^{13,14,15}$. This informed the World Health Organization (WHO) policy statement that all HIV infected children less than 24 months be commenced on highly active anti-retroviral therapy (HAART) as soon as HIV diagnosis is made. Surprisingly, HIV infected children still present late at health facilities ${ }^{16}$. Virologic testing for confirming HIV infection in children less than 18 months is still a challenge. While antibody testing is unreliable, virologic testing is not yet widely available in SSA. In most of the countries of SSA, DNA PCR testing is restricted to tertiary health facilities ${ }^{8}$. Other facilities are required to collect sample as dried blood spot (DBS) and log them to bigger facilities that have DNA PCR machine. Only few countries like Botswana can currently boost of wide spread access to dried blood spot (DBS) testing ${ }^{6}$ This increases the turn-around time for returning test results. Even the facilities that have the machines rarely return results promptly. Other challenges and concerns include drug related, psycho-social, reproductive health concerns, infant feeding choices and lack of effective HIV vaccine. These are discussed further.

\section{Psycho-social issues}

The ARVs may be free in most settings but some families still travel long distances to receive care and treatment ${ }^{17}$. Often times, appointments and subsequently ARV medications are missed because of lack of resources for transportation which leads to loss to follow up ${ }^{17}$. A multi-center study involving six West African countries and 2170 HIV infected children on ARVs documented a program loss to follow up of $23.1 \%$ at one year ${ }^{18}$. The figure will likely be higher as these children stay longer in the program. It is also not uncommon to see young children and adolescents on ARV who are unaware of why they are on these drugs. Most times, parents and caregivers shy away from issues of HIV disclosure to infected children despite possible benefits. In another multi-center study involving 650 adolescents aged 10 to 21 years in three West African countries (Côte d'Ivoire, Mali and Senegal), two-third 
of the HIV-infected adolescents on ART were not aware of their HIV status but disclosed HIV status improved retention in care $^{19}$. In Addis Ababa, a cross-sectional survey involving 172 parents / caregivers of HIV-infected school-age children showed that only $16.3 \%$ of HIV-infected school children knew their diagnosis ${ }^{20}$. Non-HIVdisclosure to children has implications for adherence to therapy, resistance and treatment failure. Haberer et $\mathrm{al}^{21}$ in a study in Zambia noted that older children (9-15 years) with no knowledge of their HIV diagnosis are at risk of treatment failure due to poor adherence. Poor adherence to ARVs for whatever reason contributes to drug resistance and treatment failure. Studies have shown rising rate of first-line treatment failures among children on $\mathrm{ARVs}^{22}$. In the event of treatment of failure, there aren't too much other available ARV options. Another devastating psycho-social issue is stigma and discrimination which has remained pervasive in most African countries ${ }^{23}$. It is a powerful barrier to scaling up and increasing access to PMTCT and pediatric HIV diagnosis, treatment, and care ${ }^{23}$. Stigma and discrimination can contribute to non-adherence and non-disclosure, thereby potentially increasing the risk of treatment failure.

\section{Drug-related challenges}

Although the majority of SSA countries have moved to pediatric treatment options that considers maternal and infant exposure to PMTCT ${ }^{24}$, there are still challenges with complex ARV regimens, pill burden, drug storage and palatability, drug stockout, treatment interruption or poor adherence, poor retention on first line ARV regimen, lost to followup, treatment failure and HIV drug resistance in the pediatric population ${ }^{8,25}$. Resistance to commonly used drugs such as nevirapine and ritonavir has been widely reported among African children on first or second line ART ${ }^{11,12}$ but less with Efavirenz and LPV/ $\mathrm{r}^{26,27}$.

\section{Malnutrition}

Malnutrition and infections interacts with HIV disease in a complex cyclical way to contribute to significant morbidity and mortality ${ }^{28-30}$. There is still an unacceptable high burden of malnutrition in countries of Africa ${ }^{31,32}$, as well as preventable diseases like malaria, tuberculosis, diarrhea diseases and acute respiratory tract infections. Severe respiratory tract infections and malnutrition have been shown to be associated with increased HIV mortality ${ }^{28-30}$. Malnutrition among HIV infected children epitomizes the level of hunger and poverty in Africa. The use of Ready-to-Use Therapeutic foods such as plumpy nuts to combat severe acute malnutrition (SAM) in HIV infected children is commendable but again, it is largely donor driven ${ }^{33}$.

\section{Reproductive health}

One of the greatest reproductive health concerns of HIV infected women is how to ensure HIV free survival for their babies. Infant feeding choices in the context of HIV has particularly been a debated issue. The WHO 2010 Rapid Advice on HIV and infant feeding is a welcome development and promises to reduce the morbidity and mortality associated with not breastfeeding children in the subcontinent ${ }^{34}$. This will however require further scientific evaluation such as acceptance rate by mothers, adherence of mother/child pair to antiviral prophylaxis during the breastfeeding period, possibility of nevirapine resistance in future and eventual outcome in terms of infection rate, morbidity and mortality. A recent study in Zimbabwe noted that implementing the 2010 Rapid Advice could substantially reduce infant HIV infection but will fall short of WHO target MTCT risk of less than $5 \%$ unless strategies that improve PMTCT uptake, retain women in care, and support medication adherence throughout pregnancy and breastfeeding are put in place ${ }^{10}$. Another option currently on the table but has not been recommended formally is triple ARVs for HIV infected pregnant women starting as soon as HIV is diagnosed, regardless of CD4 count, and continued for life while the infant receives daily NVP or AZT from birth through age 4-6 weeks regardless of infant feeding method $^{35}$. As HIV infected children transit to adolescents and young adults, there is also the delicate balancing of their sexual and reproductive health needs on one side and the avoiding risk of HIV super-infection, infecting others and MTCT.

\section{Sustainability}

The greatest challenge facing HIV services in SSA is the issue of sustainability when donors withdraw their supports. With the economic down turn around the world and rising domestic challenges within donor countries, the question is not if, but when will the donors pull out. More than a decade after the Abuja declaration that member nations of the African Union should increase health expenditure to $15 \%$, only few countries have honored that 
commitment [36]. Unacceptable high levels of corruption within and outside the governments still exist resulting in persistent poor health care delivery in the continent ${ }^{37,38}$.

\section{Eliminating pediatric HIV in SSA: Way Forward}

The government of African nations should rise and not only contribute resources to fighting HIV/AIDS but also strengthen their health systems in line with international standards. The future fight against pediatric HIV in SSA should focus on cost effective preventive strategies. HIV/AIDS is as much a social problem as it is a medical problem. Eliminating pediatric HIV in SSA will require a health promotion approach that involves combination of the five models described by Naidoo and Willis ${ }^{39}$. These five models are medical, educational, behavioral, social or radical change and empowerment ${ }^{39}$ and if collectively applied will provide a holistic intervention towards near or total elimination of pediatric HIV in Africa.

\section{Medical model}

In the medical model, we need to ensure universal access of evidence based scientific interventions that could prevent MTCT of HIV. Every pregnant woman in the SSA should have access to PMTCT services including family planning within walking distances in their communities. Those that are HIV infected should be guaranteed a continuum of care for themselves and their babies.

DNA PCR technology should be scaled up to provide a wider coverage and reduce the turnaround time of retrieving test results to days. There is therefore, the need for research to produce cheaper technologies for DNA PCR testing or suitable alternative rapid tests with high sensitivity and specificity. This is one sure step towards effective implementation of the new WHO policy of early anti-viral therapy for infected children. In a recent study designed amongst other things to assess the accuracy of 5 rapid tests for detecting HIV exposure, Sherman et $\mathrm{a}^{40}$ found that only Insti HIV-1 (BioLytical Laboratories, British Columbia, Canada) fulfilled the WHO recommendation of a minimum sensitivity of $99 \%$ and specificity of $98 \%{ }^{24,35}$ although the authors recommended further evaluation in infants. Recent evaluation has also demonstrated that inexpensive, portable and battery-operated pointof-care CD4+ T cell testing technologies showed high sensitivity and negative predictive value ${ }^{41}$. This can potentially help in reducing delays in linkage to care and ART initiation at the community level.

We also need more focused research in the area of cheaper and more palatable but effective first and second line anti-retro-virals with reduced dosing frequency and minimal drug-drug interactions. Scaling up of pediatric ART treatment in SSA need to urgently consider simple fixed-dose combinations and child-friendly adapted formulations, such as dispersible tablets, improved palatability and heat stable formulations. Examples include the need for ritonavir-boosted atazanavir and heat-stable ritonavir-boosted lopinavir in palatable pediatric formulations ${ }^{42}$.With the rising number of treatment failures among children on ARVs in SSA ${ }^{26,27,42}$, there is the need to improve treatment failure detection. The use of clinically validated, kit-based genotyping assays in SSA limit HIV drug resistance testing due to cost and the possible lack of a steady supply of test reagents ${ }^{29}$. The alternative use of dried blood spots promises to be a more cost effective alternative. A recent clinical trial that compared DBS testing and conventional plasma genotypes reported a $100 \%$ concordance ${ }^{43}$. However, further research will be required in this area.

It is also interesting to note that micronutrients may have significant roles in reducing the burden of HIV. A recent clinical trial in Tanzania involving 884 HIV infected pregnant women showed that children born to women with low vitamin $\mathrm{D}$ levels had a $61 \%$ higher risk of dying during follow up ${ }^{44}$. Cautiously though, while vitamins B, C, D and E have been found to delay HIV disease progression, a review has noted that vitamin A could double the risk of mortality in infants exposed to HIV via breastfeeding and high dose of zinc may have a positive effect on production of infectious virus through its action on the reverse transcriptase enzyme $^{45,46}$.

The capacity of every health care worker therefore, should be built to be able to identify and manage HIV infected/affected children and their families. We need to move from the current HIV stand-alone services to an approach that is integrated with the management of other maternal and childhood diseases ${ }^{47}$. With the current human resource for health crises in SSA, an effective strategy to pediatric HIV scale up, follow up and improved retention will be decentralization and task shifting ${ }^{48}$. A systematic review has shown that task shifting of some HIV services offers high-quality, cost-effective care to more patients than a physician-centered model $^{48}$.

African Health Sciences Vol 12 No 3 September 2012 


\section{Behavioral change and Social model}

There is an overlap of behavioral and social change models; and one can influence the other. We need to address the several cultural and anthropological issues that fuel HIV vertical transmission and militate against pediatric management of HIV/AIDS in SSA. These include gender inequality, trans-generational sex, premarital sex, unprotected and dry sex, multiple sexual partners, and "widow cleansing" 49-51. In countries like Cote d' Ivoire, Uganda and Rwanda, the rate of unintended pregnancies among HIV positive women is considerable high but avoidable ${ }^{52}$. The other aspect that requires urgent attention is unregulated complementary and alternative practices that delay/discourage prompt access to and continued HIV care/services ${ }^{49}$. Charlatans that prescribe sex with virgins and children as a cure for HIV are helping to increase HIV transmission ${ }^{49}$.

\section{Empowerment}

Perhaps, no other disease has brought out the need to empower families as a disease preventive strategy like HIV. HIV wears the mask of illiteracy and poverty to create a vicious cycle ${ }^{53,54}$. Educating the youths especially girls will mean greater awareness of health and their health needs, possible better jobs and guaranteed economic empowerment later in life. It is also important that pregnant women are constantly educated on the best practices to limit MTCT using the health facilities and other resources within the community such as peer counselors to support exclusive breastfeeding, support groups and community based organizations ${ }^{55}$. HIV infected children need to better understand their infection and manage their status using various coping strategies such as peer support groups, selective disclosure, religion and acceptance ${ }^{56}$.

\section{Radical change model}

Radical changes need to happen in order for the continent to be able to control the HIV scourge. Allocation of national resources to pediatric HIV/ AIDS has often failed to keep pace with the need and this gap should be addressed. The whole health systems in SSA is in dire need of overhaul and is characterized by out of pocket payments for health services, inefficient health insurance policies, decayed and dilapidated infrastructures at health institutions and lack of substantial investment in human resource for health ${ }^{57,58}$. In terms of funding, the rest of SSA should borrow a leaf from Kenya, Namibia, Sierra Leone and Uganda; where domestic spending on
HIV/AIDS rose by more than 100 percent between 2006 and $2011^{59}$. In Botswana, Comoros, Mauritania, Mauritius, the Seychelles and South Africa, domestic investment accounted for more than 70 percent of AIDS funding ${ }^{38,59}$. This is commendable but needs to be cascaded in the SSA's entire health systems in order to not only eliminate pediatric HIV but also achieve the millennium development goal 4 of a two thirds reduction in child mortality by $2015^{60}$.

\section{Conclusion}

Significant progress has been made in the fight against pediatric HIV/AIDS in SSA but there are still specific challenges militating against its total elimination. These include insufficient and delayed uptake of HIV services, drug-related and psycho-social issues, and dysfunctional health systems. In this review, a five model health promotional approach is being advocated as the strategy for elimination of pediatric HIV in SSA.

\section{Acknowledgement}

I am grateful to Dr Conrad Cole of the Division of Gastro-enterology, Hepatology and Nutrition, CCHMC, Cincinnati, Ohio for proof reading the article and making valuable suggestions.

\section{References}

1. Killian MS, Levy JA. HIV/AIDS: 30 Years of progress and future challenges. Eur. J. Immunol 2011; 41: 3401-3411.

2. WHO: Global HIV/AIDS Response: Epidemic update and health sector response towards universal access. Progress report 2011. WHO, UNAIDS, UNICEF 2011. [Online]. Available from: http://www.who.int/hiv/pub/ progress report2011/en/index.html. (Accessed May 4, 2012).

3. US Global Health Policy. Fact Sheet: The Global HIV/AIDS Epidemic. December 2010. [Online]. Available from: http://www.kff.org/ hivaids/upload/3030-15.pdf. (Accessed May 30, 2012).

4. Taylor M, Meyer-Weitz A, Jinabhai CC, Sathiparsad R. Meeting the challenges of the Ottawa Charter: comparing South African responses to AIDS and tobacco control. Health Promotion International 2009; 24: 202-210.

5. USAID. Orphan and Vulnerable Children in in High HIV Prevalence Countries in Sub-Saharan Africa. [Online]. Available from: http:// 
www.measuredhs.com/pubs/pdf/as15/ as15.pdf. (Accessed May 30, 2012).

6. Harvard Medical School. Cases in Global Health Delivery. Botswana's Program for Preventing Mother-to-Child Transmission of HIV. 2011, pp1-25.

7. WHO: Treatment of children living with HIV. WHO 2012. [Online]. Available from: http:// www.who.int/hiv/topics/paediatric/en/ index.html. (Accessed May 5, 2012).

8. Lallemant M, Chang S, Cohen R, Pecoul B. Pediatric HIV - A neglected disease? N Engl J Med 2011; 365 (7); 581-3.

9. Leach-Lemens C. South Africa's PMTCT programme reduces mother-to-child transmission to under 4\%. Aidsmap 2012. [Online]. Available from: http:// www.aidsmap.com/South-Africas-PMTCTprogramme-reduces-mother-to-childtransmission-to-under-4/page/1880446/. (Accessed May 20, 2012).

10. Ciaranello AL, Perez F, Keatinge J, Park J, Engelsmann B, Maruva M, Walensky RP, Dabis F, Chu J, Rusibamayila A, Mushavi A, Freedberg KA. What will it take to eliminate pediatric HIV? Reaching WHO target rates of mother-to-child HIV transmission in Zimbabwe: A model-based analysis. PLoS Med 2012; 9: 1-15.

11. Connor EM, Sperling RS, Gelber R, Kiselev P. Scott G., O'Sullivan MJ et al: Reduction of maternal-infant transmission of Human Immunodeficiency Virus Type 1 with Zidovudine treatment. N Engl J Med 1994, 331:1173-1180.

12. Musoke P. Recent advances in prevention of mother-to-child transmission of HIV. Afr Health Sci. 2004; 4(3): 144-145.

13. Violari A, Cotton MF, Gibb DM, Babiker AG, Steyn J, Madhi SA, Jean-Philipe P, Mcintyre JA. Early anti-retroviral therapy and mortality among HIV infected infants. N EngJ Med 2008; 359: 2233-2244.

14. Desmonde S, Coffie P, Aka E, Amani-Bosse C, Messou E, Dabis F, Alioum A, Ciaranello A and Leroy V. Severe morbidity and mortality in untreated HIV infected children in a paediatric care programme in Abidjan, Côte d'Ivoire, 2004-2009. BMC infectious disease 2011; 11: 182

15. Asfawesen GY, Solomie J, Bisirat T, Berhanu GM, Mebratu B, Rahlenbeck S. Outcome in a paediatric cohort receiving ART in Addis Abeba, Ethiopia. Acta Paediatrica 2011; 100: 1164-1167.

16. Boender TS, Sigaloff KCE, Kayiwa J, Musiime V, Calis JCJ, Hamers RL, Nakatudde LK, Khauda E, Mukuye A, Ditai J, Geelen SP, Mugyenyi P, Rinke de Wit TF, and Cissy Kityo C. Barriers to initiation of pediatric HIV treatment in Uganda: A mixed-method study. AIDS Res Treat. 2012; 2012: 817506.

17. The Rwanda Focus. ART treatment saves life but many patients are still excluded. [Online]. Available from: http://focus.rw/wp/2009/ $08 /$ art-treatment-saves-lives-but-manypatients-are-still-excluded/. (Accessed July 30, 2012).

18. Ekouevi DK, Azondekon A, Dicko F, Malateste K, Touré P, Eboua FT,Kouadio K, Renner L, Peterson K, Dabis F, Signaté Sy H, Leroy V. 12-month mortality and loss-toprogram in antiretroviral-treated children: The IeDEA pediatric West African Database to evaluate AIDS (pWADA), 2000-2008. BMC Public Health 2011; 11:519.

19. Arrivé E, Dicko F, Amghar H, Aka AE, Dior H, Bouah B, Traoré M, Ogbo P, Dago-Akribi HA, Eboua TKF, Kouakou K, Sy HS, Alioum A, Dabis F, Ekouévi DK, Leroy $\mathrm{V}$ and for the Pediatric IeDEA West Africa Working Group. HIV status disclosure and retention in care in HIV-Infected adolescents on antiretroviral therapy (ART) in West Africa. PLoS One 2012; 7(3): e33690.

20. Abebe W, Teferra S. Disclosure of diagnosis by parents and caregivers to children infected with HIV: prevalence associated factors and perceived barriers in Addis Ababa, Ethiopia. AIDS Care: Psychological and Socio-medical Aspects of AIDS/HIV 2012; 24 (6).

21. Haberer JE, Cook A, Walker SA, Ngambi M, Ferrier A, Mulenga V, Kityo C,Thomason M, Kabamba D, Chintu C, Gibb DM, Bangsberg DR. PLOS ONE 2011; 6: 1-8.

22. A biregional survey and review of first-line treatment failure and second-line paediatric antiretroviral access and use in Asia and southern Africa. Journal of the International AIDS Society 2011, 14:7.

23. Global AIDS Alliance. Accelerating actions to end pediatric HIV/AIDS by 2015. A status report 2010. [Online]. Available from: http:// a idsa $11 \mathrm{iance} .3 \mathrm{cdn}$. net/ 
c4448808bc953b94c7 3dm6vd8hq.pdf. (Accessed August 4, 2012).

24. WHO. Antiretroviral Therapy for HIV infection in children and infants: Toward Universal Access. Recommendations for a public health approach. 2010 revision. [Online]. Available from: http:// whqlibdoc.who.int/publications/2010/ 9789241599801 eng.pdf. (Accessed July 17, 2012).

25. WHO. Uganda edges closer to AIDS treatment for all. Bulletin of World Health Organization. [Online]. Available from: http://www.who.int/ bulletin/volumes/86/6/08-020608/en/ index.html. (Accessed July 30, 2012).

26. Davies MA, Moultrie H, Eley B, Rabie H, Van Cutsem G, Giddy J, Wood R, Technau K, Keiser O, Egger M, Boulle A. Virologic failure and second-line antiretroviral therapy in children in South Africa - The IeDEA Southern Africa Collaboration. I Acquir Immune Defic Syndr. 2011 Mar;56(3):270-8.

27. Zyl GU, Rabie H, Nuttall JJ, Cotton MF. It is time to consider third-line options in antiretroviral-experienced paediatric patients. Journal of the International AIDS Society 2011; 14:55.

28. Zanoni BC, Phungula T, Zanoni HM, France $\mathrm{H}$, Feeney ME. Risk factors associated with increased mortality among HIV Infected children initiating antiretroviral therapy (ART) in South Africa. PLoS ONE 2011; 6: 1-6.

29. Preidis GA, McCollum ED, Mwansambo C, Kazembe PN, Schutze GE, Kline MW. Pneumonia and Malnutrition are Highly Predictive of Mortality among African Children Hospitalized with Human Immunodeficiency Virus Infection or Exposure in the Era of Antiretroviral Therapy. J Pediatr 2011; 159: 4849 .

30. Munyagwa M, Baisley K, Levin J, Brian M, Grosskurth H and Maher D. Mortality of HIVinfected and uninfected children in a longitudinal cohort in rural south-west Uganda during 8 years of follow-up. Tropical Medicine and International Health 2012, 00: 1-7.

31. Ubesie AC, Ibeziakor NS. High burden of protein-energy malnutrition in Nigeria: Beyond the health care setting. Ann Med Health Sci Res 2012; 2: 66-9.

32. Ubesie AC, Ibeziako NS, Ndiokwelu CI, Uzoka CM, Nwafor CA. Under-five Protein Energy Malnutrition Admitted at the University of In Nigeria Teaching Hospital, Enugu: a 10 year retrospective review. Nutrition Journal 2012; 11: 43.

African Health Sciences Vol 12 No 3 September 2012
33. Guimón, José ; Guimón, Pablo. Innovation to fight hunger: The case of Plumpy'nut. SMARTech 2009. [Online]. Available from: http://smartech.gatech.edu/handle/1853/ 36636. (Accessed August 2, 2012).

34. WHO. Rapid advice: use of antiretroviral drugs for treating pregnant women and preventing HIV infection in infants. 2010. [Online]. Available from: http://whqlibdoc.who.int/publications/ $2009 / 9789241598934$ eng.pdf. (Accessed August 4, 2012).

35. WHO. Use of Antiretroviral Drugs for Treating Pregnant Women and Preventing HIV Infection in Infants. Executive Summary. April 2012. [Online]. Available from: http://www.who.int/ hiv/PMTCT_update.pdf (Accessed July 17, 2012).

36. Bodipe K. Need for African governments to increase health spending. Health-e. [Online]. Available from: http://www.health-e.org.za/ news / article.php?uid $=20032879$. (Accessed July 30, 2012).

37. Ayodele T. Africa: Why Public Health Programs Are Failing. Global Integrity, 2008. [Online]. Available from: http://www.globalintegrity.org/ node/153. (Accessed July 25, 2012).

38. The World Bank. Silent and lethal: How quiet corruption undermines Africa's development efforts. Africa's development indicators, 2010. [Online]. Available from: http:// siteresources.worldbank.org/AFRICAEXT/ Resources/english essay adi2010.pdf. (Accessed July 25, 2012).

39. Naidoo J \& Wills J. Health Promotion Foundations for Practice. 2nd Ed. Balliere Tindall, London 2002.

40. Sherman GG, Lilian RR, Coovadia AH. The performance of 5 Rapid HIV Tests Using Whole Blood in Infants and Children: Selecting a test to achieve the clinical objective. Pediatr Infect Dis J 2012; 31: 267-272.

41. Manabe YC, Wang Y, Elbireer A, Auerbach B, Castelnuovo B. Evaluation of Portable Point-ofCare CD4 Counter with High Sensitivity for Detecting Patients Eligible for Antiretroviral Therapy. PLoS One. 2012; 7(4): e34319.

42. TApHOD and IeDEA. A biregional survey and review of first-line treatment failure and secondline paediatric antiretroviral access and use in Asia and southern Africa. Journal of the International AIDS Society 2011, 14:7.

43. Ziemniak C, Mengistu Y, Ruff A, Chen Y, Khaki L, Bedri A, Simen BB, Palumbo P, Eshleman $\mathrm{SH}$ and Persaud D. Use of Dried-Blood-Spot 
samples and in-house assays to identify antiretroviral drug resistance in HIV-infected children in resource-constrained settings. Journal of Clinical Microbiology 2011; 49: 4077-4082.

44. Mehta S, Hunter DJ, Mugusi FM, Spiegelman D, Manji KP, Giovannucci EL, Hertzmark E, Msamanga GI, Fawzi WW. Perinatal outcomes, including mother-to-child transmission of HIV, and child mortality and their association with maternal Vitamin D status in Tanzania. The Journal of Infectious Diseases 2009; 200:1022-30.

45. Maggie Z, Guoping HE and Honghong HE. Effects of nutritional supplementation on children with HIV/AIDS in China. J Cent South Univ (Med Sci) 2012; 37(3): 305-7.

46. Muthuraj IM, Kamatchiyammal S, Usharani B, Manupriya S, Ayyappan ARN and Divyalakshmi K. Serum Zinc, Calcium and Albumin Levels in Pulmonary Tuberculosis Patients Co-Infected with HIV. Global Journal of Biotechnology \& Biochemistry 2010, 5 (1): 27-35.

47. Ishikawa $\mathrm{N}$, Ishigaki $\mathrm{K}$, Ghidinelli $\mathrm{MN}$, Ikeda $\mathrm{K}$, Honda M, Miyamoto H, Kakimoto K, and Oka S. Paediatric HIV and elimination of mother-tochild transmission of HIV in the ASEAN region: a call to action. AIDS Care. 2011 April; 23(4): 413-416.

48. Callaghan M, Ford N, Schneider H. A systematic review of task- shifting for HIV treatment and care in Africa. Human Resources for Health 2010, 8:8.

49. Audet CM, Burlison J, Troy TD, Sidat M, Vergara AE, Vermund SH. Sociocultural and epidemiological aspects of HIV/AIDS in Mozambique. BMC International Health and Human Rights 2010, 10:15.

50. Machel JZ. Unsafe sexual behaviour among schoolgirls in Mozambique: a matter of gender and class. Reprod Health Matters. 2001 May;9 (17):82-90 .

51. Hawkins K, Price N, Mussa F. Milking the cow: young women's construction of identity and risk in age-disparate transactional sexual relationships in Maputo, Mozambique. Glob Public Health. 2009;4(2):169-82 .

52. Kikuchi K, Wakasugi N, Poudel1 KC, Sakisaka K, Jimba1M. High rate of unintended pregnancies after knowing of HIV infection among HIV positive women under antiretroviral treatment in Kigali, Rwanda. BioScience Trends. 2011; 5(6):255-263
53. John Seager, Thulisile Ganyaza-Twalo, Tsiliso Tamasane (n.d.) Conceptual Framework to Help Understand the Interactions between Poverty and HIV/AIDS. [Online]. Social Aspect of HIV and AIDS Research Alliance (SAHARA). [Online]. http://www.sahara.org.za/activities/a-study-ofthe-relationships-between-poverty-and-hiv-aids. (Accessed August 4, 2012).

54. Ganyaza-Twalo, T. \& Seager, J. (2005) Literature Review on Poverty and HIV/AIDS: Measuring the Social and Economic Impacts on Households. Unpublished paper of the Human Sciences Research Council. Available from: Social Aspect of HIV and AIDS Research Alliance (SAHARA). [Online]. http://www.sahara.org.za/activities/astudy-of-the-relationships-between-poverty-andhiv-aids. (Accessed August 4, 2012).

55. Busza J, Walker D, Hairston A, Gable A, Pitter C, Lee S, Katirayi L, Simiyu R, Mpofu D. Community-based approaches for prevention of mother to child transmission in resource-poor settings: a social ecological review. I Int AIDS Soc. 2012 Jul 11; 15 (4):1-11.

56. Stutterheim SE, Bos AE, Shiripinda I, de Bruin M, Pryor JB, Schaalma HP. HIV-related stigma in African and Afro-Caribbean communities in the Netherlands: manifestations, consequences and coping. Psychol Health. 2012; 27 (4):395-411.

57. WHO. Health systems strengthening in the African region. The African Health Monitor, 2010. [Online]. http://ahm.afro.who.int/issue12/ahm12.pdf. (Accessed August 4, 2012).

58. Sekhri N. From funding to action: strengthening health care systems in sub-Saharan Africa. World Economic Forum. [Online]. https:// members.weforum.org/pdf/whitepaper.pdf. (Accessed July 30, 2012).

59. IRIN: AFRICA: Domestic investment in HIV up but uneven. Plus News Global 2012. [Online]. http://www.irinnews.org/Report/95904/ AFRICA-Domestic-investment-in-HIV-up-butuneven. (Accessed August 4, 2012).

60. WHO. MDG 4: reduce child mortality. [Online]. http://www.who.int/topics/ millennium development goals/child mortality/ en/. (Accessed August 4, 2012). 